\title{
Black and Blues: Sub Drop, Top Drop, Event Drop and Scene Drop
}

\author{
Richard A. Sprott, Ph. D. \\ California State University, East Bay \\ Anna Randall, MSW, MPH, DHS \\ The Alternative Sexualities Health Research Alliance
}

A couple of days after a magnificent BDSM scene with her Dominant, KittyK feels unusually sad and insecure. While it was one of the high points of her D/s relationship with SirStephan, "I feel a little lost and unconnected, maybe even a bit embarrassed, even though Sir has been so attentive," she reports.

Then there is Samuel, who attends his first full weekend kink/leather event - filled with valuable classes and exciting play parties. He connects with some awesome people and gets a sense of being immersed in this world that he has always dreamed about; he feels a great sense of belonging. A few days later, after he gets back to his everyday work and home life, he finds it hard to concentrate, he feels exhausted, and he lacks interest in the usual things that bring him pleasure and satisfaction. ${ }^{7}$

It is not unusual to hear descriptions like this when a person spends time in various kink, BDSM and leather communities. For some people, after having a wonderful, energetic, amazing kink/BDSM experience, they seem to have some sort of letdown, emotional downturn or crash. This appears to happen to people from different cultural backgrounds, and across genders and orientations and ages. Within the kink world, these post-event occurrences are often labeled with terms like "sub drop" or "event drop" - as well as "Top drop" or "Dom drop". These terms are used to describe many different kinds of feelings, involve many time frames; from minutes to days after. What exactly is this experience? As researchers with a keen desire to better understand the kink experience and how this understanding can translate to clinical practice, this paper is an enquiry into what drop might signify.

\section{In the Moment.....the term "drop" may be ambiguous}

Many people in the kink communities talk about "sub drop" or "Top drop" as an exhaustion or refractory phase of an intense scene, as the moment when "all the endorphins and adrenaline are settled down again." (Charisma, n.d.)

"Since the increase of hormones and chemicals has produced a trance-like state, as play ends the submissive may feel out-of-body, detached from reality. As the sub's system

\footnotetext{
${ }^{7}$ These two case descriptions are each an amalgamation of several clients' experiences. They are not descriptions of individual people or their experiences.

${ }^{8}$ In keeping with a kink community practice, we are using capitalization to indicate submissive roles (lowercase) and Dominant roles (uppercase).
}

Journal of Positive Sexuality, Vol. 2, November 2016@ 2016 Journal of Positive Sexuality-Center for Positive Sexuality 
stops producing morphine-like drugs, and as the parasympathetic nervous system kicks in again, the sub may feel a deep exhaustion, a sharp drop in temperature, as well as incoherence and un-coordination. In the lifestyle, this is commonly referred to as 'drop' or 'sub-drop'”, (Dexter, 2012).

"As the high comes down, and the parasympathetic nervous system kicks in (to counteract the effects of the aforementioned chemicals), a deep exhaustion, as well as incoherence may result." (asibdsm, 2013).

The above quotes are some of the prevailing descriptions of the experience of "Top drop", "scene drop" and "sub drop" mentioned by kink educators, online blogs and informational sites. These descriptions capture what some individuals feel immediately after a kink scene. There are others who describe another phenomena, a later onset of sub drop or event drop that can happen hours or days after a scene. We propose the term "x-drop" to refer to all four types of drop: sub drop, Top drop, event drop, and scene drop.

The kink subculture seems to have accepted the above lay explanation for the first kind of $\mathrm{x}$-drop that happens at the end of a scene or near the end of a scene. The biochemical proposal, involving the sympathetic and parasympathetic systems and hormonal fluctuations, seems to be relevant especially for a sub or bottom who is receiving intense sensation and experience. However, we also point out that there is no research to test these ideas about the physiological profile of the immediate $\mathrm{x}$-drop, and in fact one could argue that the exhaustion phase of a stress reaction is more complicated than the above physiological descriptions.

Those biological explanations are problematic, however, when it comes to the more delayed x-drop experience. Many sources, like those detailed above, often do not make a distinction between what happens at the end of an intense scene and what happens a few days later, referring to both with the same term and using the same explanation. This more delayed onset of $\mathrm{x}$-drop is typified in the examples of KittyK and Samuel at the start of this article with an emotional reaction or state that can involve guilt, anxiety, melancholy, or exhaustion. It describes an emotional reaction that usually appears several days, maybe even up to a week, later. These different onsets piqued our curiosity. What might be happening in individuals who experience these emotional changes in the days after? Perhaps there are other possible explanations about the later x-drop phenomena.

Our aim in exploring $\mathrm{x}$-drop is two-fold: to shed some light on the phenomenon so as to improve the way those who encounter $\mathrm{x}$-drop understand and cope with their experience; and to normalize, de-pathologize and perhaps even transform our comprehension of what individuals experience during x-drop, especially for clinicians (doctors, therapists, etc) who may encounter individuals experiencing $\mathrm{x}$-drop.

\section{Days Later ... Later $\mathrm{X}$-drop is not a biochemical reaction}

It is not difficult to establish that there are two different types of drop, due to differences in reported phenomenological experience, time of onset, and different behaviors people use to cope or provide care in response to the experiences. We hypothesize the immediate scene drop, at the end of an intense and demanding BDSM experience, may 
reflect various hormonal changes described by the above referenced explanations, e.g., the exhaustion phase of an intense, acute stressor experience. Undoubtedly, the hormonal changes in scene drop are more complicated than a simple adrenaline and cortisol shift, pointing to a need for more empirical studies of scene/Top/sub drop, similar to the work of Brad Sagarin and his colleagues who have studied how BDSM scenes affect cortisol and testosterone levels (Sagarin et al. 2009).

Stress is inherently neutral. Depending on context and perception, an individual may perceive the stress as positive (eustress) or negative (distress). For example, a positive reaction to stress can stimulate motivation and development, or if perceived negatively, it may produce anxiety or illness. Any stress reaction has three phases: the initial phase of flight or fight, (or "tend and befriend" or immobilization/freezing - two other possibilities for reacting to a stressor initially). This is followed by adjustment and accommodation to the heightened state of arousal, also called "resistance" phase, wherein the body adapts to functioning in this state of readiness, alertness and activation. The third phase of the stress reaction is exhaustion - as the body cannot function at this heightened level for very long, without some rest and recuperation (Sapolsky, 2004).

However, most of the common descriptions of the hormonal changes in scene drop are changes that occur in terms of minutes, not days. This is distinctly different from the drop that can happen the next day, or the day after - or two days after. These are not the exhaustion phase of an acute stress response. They seem to be related to some other dynamic.

We propose that the experience of this later $\mathrm{x}$-drop may reflect a meaningful psychological process, relatively independent of the cascade of hormones that are implicated in the more immediate experience of scene drop. Later x-drop requires a different kind of explanation. We wish to explore a few possibilities, which may lead to some new research questions and new ideas that may guide treatments by kink-competent therapists.

\section{Days Later... Later $\mathrm{x}$-drop is a reaction to loss}

When experiencing $\mathrm{x}$-drop, what is the deep psychological process that leads one to be feeling lost, ungrounded, disconnected, unsatisfied, depressed, irritable, vulnerable, raw, sad? We propose that the process may be one of grief and bereavement. X-drop may be the psychological reaction to a loss.

But what, exactly, is lost? What are people grieving after a wonderful experience, an intense scene, or a fantastic weekend with other kink-identified people who have gathered together as a community?

In order for us to make sense of the proposal that later x-drop is grief/bereavement, we first need to discuss the intense and positive experiences that seems to proceed the $\mathrm{x}$-drop. As we explore "what is lost", we also wish to point out the the reaction to a loss as proposed here is not a different process from other kinds of intense experiences and the loss reaction afterwards - the grief/bereavement reaction is not unique to BDSM. We believe the same 
process occurs in the aftermath of any intense performance or activity. We note that actors and directors in theatre often discuss a similar phenomenon (Attanasio, 2014), and athletes have noted the "post-Olympic depression" (Florio \& Shapiro, 2016).

\section{Background: Peak Erotic Experiences shape our erotic template}

Back in the 1970s, Dr. C.A. Tripp, a psychologist and sex researcher who trained with Alfred Kinsey, proposed that sexual excitement was a result of a combination of attraction and overcoming obstacles to that attraction - something he called "the erotic equation." He described that the more barriers or hurdles to jump over to reach the goal, the more intense the experience of satisfaction and pleasure felt when one fulfills the driving need to reach the object of attraction (Tripp, 1975). Interestingly, the idea of that forbidden fruit heightens desire and longing; in fact, anything that at first inhibits people sexually can later become a major turn-on. It was a theory that could explain hidden fantasies and even fetishes. People start to associate the obstacle with the erotic excitement of finallyovercoming-the-obstacle and reaching the desired object of attraction. In this paradigm, soon the obstacle itself cues people directly to experience that erotic excitement.

If this erotic equation works, then BDSM especially may work to intensify the obstacles to objects of desire, and yet also to facilitate the consummation of desires. The bondage holds a person back, but allows the person to experience being sexually taken. The willingness to brave an erotic spanking means that a person will earn the caress that one desires (whether that is the caress of endorphins or the caress of tender aftercare). The planning and preparation to Top someone else becomes a journey to sexual satisfaction, as the Top needs to acquire the skills (the hurdles) to do the scene before a person can consume the object of their desire, the satisfaction of Topping someone. Delayed gratification occurs for both the Top and bottom in a scene, although in different ways.

Thus, BDSM attempts to heighten the erotic experience by intensifying the obstacles and facilitating the overcoming of those obstacles. BDSM also strengthens the attraction and expands it to include more elements, such as the obstacles themselves (eg. the feel of the leather restraint or the skin-tight latex each facilitate increased eroticism). By working with Tripp's "erotic equation", BDSM intensifies the excitement of an erotic encounter.

Abraham Maslow first described peak experiences for psychology in 1962. "Think of the most wonderful experience of your life: the happiest moments, ecstatic moments, moments of rapture, perhaps from being in love, or from listening to music or suddenly 'being hit' by a book or painting, or from some creative moment." (Maslow, 1962, p. 9). People have often included sex/eroticism and intimacy as common triggers for peak experiences, along with nature, discovery, and extreme sports (it is not a far leap to frame "kink" as an extreme sport of sexuality) (Morin, 1995).

Adding to this understanding of how individuals create erotic interests, Jack Morin, in his 1995 book, The Erotic Mind, incorporated C.A. Tripp's concept of the "erotic equation" and John Money's theory of "love maps," to develop his own theory of core erotic themes (Morin, 1995). Comprised of earlier "erotic experiences" and significant moments of 
excitement and pleasure, our turn-ons embody early types or themes. The intensifying of the excitement made with these turn-ons means that we may be more likely to experience a "peak experience" through sex or kink activities.

Perhaps for Tops, or submissives-in-direct-service, the peak experience during a BDSM scene, may involve a state of consciousness called "flow." Mihalyi Csikszentmihalyi coined the term in the 1970s to discuss a mental state of focused motivation and attention, when a person is fully absorbed in performing a creative, challenging activity. Sometimes during, but especially afterwards, emotionally there is a positive experience of joy. One can think of "flow" as a mental state that is the opposite of depression or apathy. (Csikszentmihalyi, 1975). In her work approaching kink as serious leisure, Newmahr (2010, 2011) discusses the state of flow as a component of people's motivations to engage in kink activities.

So if individuals are experiencing peak moments or moments of flow during one of these BDSM scenes, these profound states of consciousness might be "what is lost," afterward. The incredible mental state is no more. It is gone. Perhaps what is lost is the view from the mountaintop; the moment of transcendence, or the experience of fully functioning at the higher reaches of a person's potential without inner conflict or tension, without fear, doubt, or self-criticism.

While the theory of "peak erotic experience" can address our understanding of x-drop after a scene or intense weekend of Dominance/submission, there are other kinds of peak experiences besides erotic ones. These peak experiences can be felt at the level of the group, of the community. Being in a space with others of like mind, being able to express one's self and have one's relationships fully acknowledged and supported, can be its own fulfilling experience. Often for many people, having this side of a person's sexuality and kink identity supported and expressed when, in comparison, most other spaces and events do not support or allow expression, can be powerful and very impactful. Event drop can include peak erotic experiences in the whole, but larger BDSM events usually involve a community-space (communal) brand of peak experience which are not necessarily erotic. This peak experience involves the release of a part of ourselves that we often feel necessary to keep under wraps, and so community kink events can impact our identities and self-concepts just as much as a deeply personal, individual peak erotic experience may.

We have focused on positive experiences, such as peak experiences, as this is generally the context that kink community members have discussed their experiences of $\mathrm{x}$ drop. The word "drop" itself implies going from a high point to a low point. However, there is nothing in the phenomenon or in the theoretical framework proposed here that requires a later x-drop experience to be confined to positive experiences. It raises the empirical question of whether $\mathrm{x}$-drop happens more after positive experiences than negative experiences.

\section{Two Reactions to Living After Peak Experiences: Grief and/or Identity Change}


We'd like to now focus on two possible psychological reactions to the loss of the peak experience. One is grief, the emotional reaction to a loss and bereavement that one experiences when the peak experience is over. Another reaction caused by x-drop might be a shift or change in our self-concepts, our sexual identities and/or our kink identities. We propose that both processes are possible explanations for what is happening in the process of later x-drop.

\section{Proposal A: X-drop initiates a process of grief and bereavement}

We posit that perhaps grief may be one of the sequelae of $\mathrm{x}$-drop and carries with it a process of change. "Grief" refers to the emotional and cognitive reactions that a person has when one experiences a loss or separation. Though usually thought of as different from the characteristics of clinical depression, grief can include a range of emotions like anger, sadness, longing, or acceptance. An additional accompanying reaction to loss and separation, "bereavement" refers to the adjustments and changes that a person has to manage in order to adapt to the loss that is being grieved. The experience of bereavement may include identity or role changes, changes in a person's worldview or values brought on by the experience of loss, or changes in managing and adapting to a different physical environment or context because of the effects of the loss. So, if $\mathrm{x}$-drop is a process of grief and bereavement, then the peak experience might be what is "lost." A few days later, as regular life settles in, the amazing moment is still there in our memory, in sharp contrast to our regular functioning or being.

The first person to write about "grief work" was Erich Lindemann in 1944, a psychiatrist in Boston. He described the struggles of people who were grieving the loss of loved ones in the Coconut Grove fire in 1942, the worst nightclub fire in U.S. history which killed almost 500 people. He observed themes common to these grieving people. They were struggling with guilt and regret, often preoccupied with their loss, and were confused and angry. The work of grief allowed them process their grief, make adjustments to their loss and then make new relationships. He also discussed the importance of creating new roles and new identities in the bereavement process. (Lindemann, 1944).

In applying this grief concept to the feeling of $\mathrm{x}$-drop, we wonder: Do some people experience guilt afterwards? If not guilt, what about regret? Guilt and regret both involve the wish that things could or should have been different. Perhaps people after an important, positive kink experience ask themselves, "Why did I wait this long? Did I do the right thing? Why did I listen to all those people who said I shouldn't embrace my sexual desires? Why did I not listen to my gut or my heart?".

Lindemann's work led to additional theories about grief, including one by psychiatrist Elizabeth Kubler-Ross, who in 1969 initially described observable "stages of grief" in her work with patients who had terminal illness. Later, she recognized that "stages" was imprecise, because it implied a linear progression (and in developmental psychology, a stage theory proposes that a person cannot go back to previous stages, because each stage is a significant transformation of the person that cannot be undone by going backwards). Her approach outlined different states of mind in grief: denial, bargaining, anger, depression and 
acceptance. She described the denial, bargaining and anger phases as the grieving person's attempting to control the situation and make the loss go away, in an attempt to preserve the way things were. Her depression and acceptance phases involve mourning, the adjustment to the loss, and the acceptance of it. (Kubler-Ross, 1969).

Is it possible that feeling $\mathrm{x}$-drop might be about "trying to preserve" an individual's recent peak experience, or the need to let the experience go when people accept that their wish to preserve or maintain it cannot be realized? In x-drop, do people experience any states that parallel bargaining, e.g. "If I do it again, exactly like before, can I have that experience again!") in their later x-drop? Some people talk about having experiences like dissociation when they have later $\mathrm{x}$-drop — is that a kind of denial? Some people talk about heightened irritability as characteristic of their x-drop experience - isn't that an anger phase?

Another theory about grief is the Parkes-Bowlby approach. Colin Parkes, in the 70s and $80 \mathrm{~s}$, proposed four phases of grief, based on the attachment theory articulated by John Bowlby and his colleagues (Parkes, 2015). First, there is a numbness/shock phase. The loss involves a deep change in how a person organizes and orients their life (attachments are emotional bonds that allow humans to create a sense of "home" or "safe space" that they then can venture out from, explore the world, and return to). A second phase is "yearning and searching" where the person attempts to reunite with the lost attachment figure or secure base. This is an attempt to "preserve" the way things were. A third phase is "disorganization and despair" wherein the person accepts the loss and lets go of the old way of orienting their world. Then a fourth phase of "reorganization and recovery" when a person establishes a new secure base or emotional home. If x-drop involves a loss of a secure base or sense of home, if it involves the loss of attachments, then perhaps this grief process is implicated in $\mathrm{x}-$ drop. Perhaps an intense BDSM experience can bring up memories of lost attachments, so that what is lost is not the peak experience itself, but coming into touch with past losses and grief. The different headspace or state of mind in the peak experience allows the past to come to the surface.

\section{Proposal B: Identity Development}

So far, current psychological theory would suggest a grief or bereavement process because of either the loss of a peak experience state, or the loss of an attachment. But what if the person has lost an identity? A sense of themselves, at least an old way of seeing themselves? Perhaps, for some people, later $\mathrm{x}$-drop is a process of identity change.

Erik Erikson's psychosocial theory proposes that people's development should be thought of as an ongoing process of identity - that in fact "identity" itself is an ongoing process, not a thing one "has" or "possesses" like an object. It is a process of reconciling one's unique properties and characteristics with the social expectations and pressures which we are surrounded by all the time. Internally, the process of identity is how one balances the need to belong and connect with the need to be empowered, autonomous and selfauthoritative. This balancing has to occur every day, especially as the individual changes (a person's body grows and ages; a person's interests shift), and as society changes (Erikson, 1968). Hence identity can shift as the person and the social environment changes. And one 
has multiple identities, but some identities are more central to us, to our sense of self, than others. If those change, then it can be felt as a seismic experience.

Robert Kegan (1982) proposed a theory of self development that synthesized Erikson's theory with Jean Piaget's constructivist theory of cognitive development. The Self is the way in which we make sense of the world, of our experience - how we make meaning. The Self undergoes stage-like transformations as a person develops. Kegan noted in his book that a stage change can involve what he called "developmental depression": a person has lost the old way of making sense of the world, but the new way isn't here yet, has not yet been established. In this in-between, one can experience things has disorienting, deeply unsatisfying, scary, confusing. Old behaviors, relationships, interests, values and worldviews feel fake or constricting or one feels disconnected, lonely.

Is this what later $\mathrm{x}$-drop is about? One's self, or a central identity, is changing in some way. And that change involves a loss of the old self, the old identity. And hence grief as a reaction to that loss.

\section{Conclusion}

We propose that the later kind of $\mathrm{x}$-drop is not a biochemical process as much as it is a process of loss and grief, or a reaction to loss that is part of identity change. Perhaps the later $\mathrm{x}$-drop is a sign of growth, but a growth process that involves negative emotional experiences as part of the change. X-drop becomes the felt aspect of the challenge of incorporating the peak experience into one's life. Or integrating past losses into one's present life. Or it is the felt aspect of identity change. In either case, the experience of drop may be a healthy process and may not be a sign of something going wrong, may not be a sign of pathology or dysfunction.

BDSM in particular may heighten the "erotic equation" that heightens the possibility of a peak experience: BDSM scenes often involve some sort of barrier or constriction (physical and/or psychological barriers) that is then overcome, so that the person finally consummates their desire, achieves erotic release. This intensified experience may result in peak experiences which then can have significant impact on one's consciousness, identities, relationships, intimacies, etc. And then the experience is over, and so it would not be unusual to experience a loss, with a resultant grief process.

Clearly there is more research needed, both biological and psychological, to examine this relatively common phenomenon. There are some possible immediate research questions to be addressed: Does later x-drop occur more frequently after positive kink experiences rather than negative kink experiences? Are some individuals more prone to experience later $\mathrm{x}$-drop than others? What are the physiological processes occurring during the $\mathrm{x}$-drop experience, and are these processes different between immediate $\mathrm{x}$-drop and later $\mathrm{x}$-drop? What exactly are the emotional dynamics of later x-drop, and do they involve regret, guilt, or bargaining? Does later $\mathrm{x}$-drop involve identity change? We believe that this is necessary work, because it would be easy for doctors, therapists, and psychologists to interpret the drop experience as a sign of dysfunction, illness or disorder, leading them to an interpretation of 
BDSM behaviors and activities as being pathogenic or clearly dangerous to people's mental health. We hope these proposals point to a non-pathologizing way of understanding $\mathrm{x}$-drop.

Asibdsm (2013). Subspace and aftercare. [blog post]. Retrieved from http://asibdsm.com/subspace-after-care/

Attanasio, A. (2014). Post theatre blues: when the show is over. [blog post]. Retrieved from http://kidzkonnectionct.org/post-showdepression/

Charisma, A. (n.d.) Aftercare [blog post]. Retrieved from http://isthisbdsm.blogspot.com/2013/09/af tercare.html

Csikszentmihalyi, M. (1975). Beyond boredom and anxiety: Experiencing flow in work and play. San Francisco: Jossey-Bass. ISBN 087589-261-2

Dexter, Dr. (2012). BDSM 101: Subspace, Aftercare, and Sub-drop (and sometimes Top-drop). [blog post]. Retrieved from http://chicomunch.com/publ/basic_info_a bout_bdsm/bdsm_101_subspace_aftercare and_sub_drop_and_sometimes_top_drop $\overline{1} 1-1-\overline{0}-23$

Erikson, E. (1968). Identity: youth and crisis. New York: Norton and Company. ISBN 9780-393-34734-0

Florio, J. and Shapiro, O. (2016, August 18). The dark side of going for gold. The Atlantic. Retrieved from http://www.theatlantic.com/health/archive /2016/08/post-olympicdepression/496244/

Kegan, R. (1982). The evolving self. Boston: Harvard University Press. ISBN 780674272316

\section{References}

Kubler-Ross, E. (1969). On death and dying. New York: Scribner. ISBN 978-1-4767-7554-8

Lindemann, E. (1944). Symptomatology and management of acute grief. American Journal of Psychiatry, 101, 141-148

Maslow, A. H. (1962). Toward a psychology of being. Princeton, NJ: Van NostrandReinhold

Morin, J. (1995). The erotic mind: Unlocking the inner sources of passion and fulfillment. New York: Harpercollins. ISBN 9780060-98428-1

Newmahr, S. (2010). Rethinking kink: Sadomasochism as serious leisure. Qualitative Sociology, 33, 313-331

Newmahr, S. (2011). Playing on the edge: Sadomasochism, risk, and intimacy. Bloomington: Indiana University Press

Parkes, C. (2015). Death and bereavement across cultures. Second edition. New York: Routledge. ISBN 978-0415522366

Sagarin, B. J., Cutler, B., Cutler, N., LawlerSagarin, K. A., \& Matuszewich, L. (2009). Hormonal changes and couple bonding in consensual sadomasochistic activity. Archives of Sexual Behavior, 38, 186-200

Sapolsky, R. (2004). Why zebras don't get ulcers. Third edition. New York: Holt. ISBN 978-0805073690

Tripp, C.A. (1975). The homosexual matrix. New York: McGraw Hill Book Company. ISBN 0-07-065201-5 